\title{
Effect of different potato varieties and tuber sizes on physiological changes under ambient storage performance
}

\author{
Archana Brar* and M. K. Rana \\ Department of Vegetable Science, CCS Haryana Agricultural University, Hisar-125 004 (Haryana), INDIA \\ *Corresponding author. E-mail: brararchanaarch@gmail.com \\ Received: September 10, 2015; Revised received: February 22, 2016; Accepted: May 9, 2016
}

\begin{abstract}
The storability and sprouting behavior of three grades (small, medium and large tubers) from four Indian potato cultivars was studied under ambient conditions to assess the quality changes due to physiological losses and sprouting bhaviour of potato tubers. It was found that physiological loss in weight (\%), decay loss on number and weight basis (\%), sprout loss on number and weight basis (\%), total loss (\%), general appearance, presence of black or hollow heart were affected significantly by the different varieties as well as by the size. The loss in weight of tubers due to physiological activities, decaying and sprouting increased with the increased in storage period and the loss was more in larger than smaller and medium tubers. Kufri Badshah showed the best control over sprouting, whereas, $100 \%$ sprouting was observed in Kufri Bahar with all possible combinations during storage. The maximum value for cumulative physiological loss in weight was observed in variety Kufri Bahar (12.07\%), whereas, minimum was in Kufri Pushkar (7.44\%). The maximum decay loss was observed in variety Kufri Pushkar $(7.89$ and $8.72 \%)$ and minimum in Kufri Bahar (0.00 and 4.58\%) on 80th and 90th day of storage period. Black or hollow heart was absent completely in all the possible treatments. So far general appearance of the tubers was concerned, the larger tubers shrivelled more and earlier than the medium and small sized tubers. Different varieties behaved differently during the entire storage period.
\end{abstract}

Keywords: Black/hollow heart, Physiological loss, Potato varieties, Sprout loss

\section{INTRODUCTION}

Potato (Solanum tuberosum L.), a member of Solanaceae family is the only non-cereal food crop to commend such a high position in the world since being nutritious food it can solve the problem of mal- and under-nutrition. The potato tubers after harvest remain dormant for sometimes and the duration of dormancy varies with the variety. Some varieties may have better keeping quality due to their morphological features and longer dormancy period than the other varieties. Cool and wet weather is known to extend the dormancy period (delay sprouting), while dry and warm weather conditions shorten it. Potatoes from crop grown under short day conditions have shorter dormancy than those grown under long day conditions_and higher storage temperature hastens dormancy release. A total of 90 percent of potato production in India is from the Indo-Gangetic plains, where the crop is harvested from January to March before the onset of long hot summer. Storage under ambient conditions in Indian plains can result in enormous losses due to attack by microorganisms. The perishable nature of potatoes coupled with increased production and insufficient cold storage facilities often result in post harvest glut and consequent crash of prices due to distress sale. In India, a large number of high yielding and disease resistant potato varieties have been developed for plains where potato harvest is followed by rising temperature in hot and dry summer. Due to inadequate and expensive refrigerated storage facility, more than half of the produce is stored at room temperature for varying periods. At room temperature, there are losses due to rottage, sprouting and shrinkage of tubers. Extent of weight loss during storage is dependent on genotype (Kang et al., 2001; Patel et al., 2006).

A total of 90 percent of potato production in India is from the Indo-Gangetic plains, where the crop is harvested from January to March before the onset of long hot summer. Storage under ambient conditions in Indian plains can result in enormous losses due to attack by microorganisms. The perishable nature of potatoes coupled with increased production and insufficient cold storage facilities often result in post harvest glut and consequent crash of prices due to distress sale. In India, a large number of high yielding and disease resistant potato varieties have been developed for plains where potato harvest is followed by rising temperature in hot and dry summer. During the peak harvesting period from February to April, prices of potatoes crash forcing farmers to go in for distress sale. The prices rise to peak during July-August. Thus, there is clear advantage in storing potatoes till June before releasing for sale. Due to inadequate and expensive refrigerated storage facility, more than half of the produce is stored at room temperature for varying periods. At room temperature, there are losses due to rottage, 
sprouting and shrinkage of tubers. Extent of weight loss during storage is dependent on genotype (Kang et al., 2001 and Patel et al., 2002). The present investigation was carried out to study the effect of different potato varieties and tuber sizes on physiological changes under ambient storage performance and to evaluate the effect of tuber size on sprouting behaviour of potato varieties and to assess the quality changes in different graded potato tubers during storage.

\section{MATERIALS AND METHODS}

This present experiment was conducted on the four cultivars of potato i.e., $\mathrm{V}_{1}$ : Kufri Badshah, $\mathrm{V}_{2}$ : Kufr Bahar, $\mathrm{V}_{3}$ : Kufri Pukhraj, $\mathrm{V}_{4}$ : Kufri Pushkar on the Complete Randomized Design (factorial) in four replication and was carried out in Laboratory of the Department of Vegetable Science, CCS Haryana Agricultural University, Hisar during spring-summer season of 2012. Undamaged and apparently healthy tubers with three sizes i.e., $\mathrm{S}_{1}$ : up to $25 \mathrm{~g}, \mathrm{~S}_{2}:>25-50 \mathrm{~g}, \mathrm{~S}_{3}:>50-75 \mathrm{~g}, \mathrm{~S}_{4}:>75 \mathrm{~g}$ weight were selected to study the keeping quality. The experiment was started by keeping $4 \mathrm{~kg}$ healthy clean tubers of three different sizes for each genotype in hessian cloth bag at room temperature in four replications. All observations were recorded at an interval of 10 days. The physiological loss in weight was calculated by weighing five randomly marked tubers from each replication after every 10 days of storage. The data were recorded after every 10 days on percent loss due to decay and sprouting based on both the number and weight. Percent sprouting was calculated from tubers having sprouts more than 2 $\mathrm{mm}$ long and sprout weight by weighing the sprouts after de-sprouting. The data were also recorded at end of the experiment on black or hollow heart (presence or absence) and general appearance (sound or shriveled).

Calculation of PLW (\%): The following formula as suggested by Srivastava and Tandon (1968) was employed to calculate the percent PLW for each date of observation.

Physiological loss in weight $(\%)=($ Initial weight - Final weight)/ Initial weight $\times 100$

Calculation of decay loss (\%): The percent decay loss was calculated according to the formula suggested by Srivastava and Tandon (1968).

Decay Loss $(\%)=(\mathrm{W}-\mathrm{w}) / \mathrm{W} \times 100$

Where, $\mathrm{W}=$ Total weight of the tubers, $\mathrm{w}=$ Weight after eliminating decayed tubers

Calculation of sprout loss (\%)

(a) On weight basis (\%): The loss due to sprouting on weight basis was calculated by the formula given as under:

Sprouting loss $(\%)=$ Weight of sprouted tubers/ Initial tuber weight $\times 100$

(b) On number basis (\%): The loss due to sprouting on number basis was calculated by the formula given as under:

Sprouting loss $(\%)=$ Number of sprouted tubers $/$ Total number of tubers $\times 100$ (c) Sprout weight (g): For the purpose, all the sprouts were separated from the tubers and weighed separately. The sprout weight (g) was calculated as:

Sprout weight $(\mathrm{g})=$ Weight of sprouts / Initial tuber weight $\times 100$

Total loss (\%): Net weight of tubers at the end of storage period was noted down and the total loss in percent was calculated by using the formula given below:

Total loss $(\%)=$ (Initial tuber weight - Net weight of tubers) / Initial tuber weight $\times 100$

(Net weight of tubers: left after removing sprouted and rotted tubers)

Diagnostic method of Black or hollow heart: The tubers are cut longitudinally from end to end. Hollow heart appears as a star-shaped, irregular cavity in the center of tubers. Brown center is characterized as a small $1 / 8$ to 1.0 inch diameter, brown, circular or elliptic, opaque area with a diffuse border along the longitudinal tuber axis.

General appearance: The acceptability of tubers (excluding decayed tubers) was assessed based on general appearance using numerical scale ranging from 5 to 0 as given by Ranganna (1977).

Where,

$0=$ Badly deteriorated $3=$ Less shriveled

$1=$ More shriveled $\quad 4=$ least shriveled

$2=$ Medium shriveled $5=$ Excellent

\section{RESULTS AND DISCUSSION}

Physiological loss in weight (\%): The data on physiological loss in weight were recorded at an interval of 10 days during storage period of 90 days and expressed as cumulative percentage (Table1). The storage of potatoes at ambient room temperature during hot summer months results in severe loss in weight and quality. The potato varieties differed significantly with respect to physiological loss in weight. The external factors affecting the intensity of transpiration are air temperature, humidity and air circulation in the storehouse. Among the varieties, significant variation was observed for physiological loss in weight throughout the storage period. These results are in accordance with the findings of Verma and Jha (1990), Kumar et al. (2005) and Gautam et al. (2012). The extent of weight loss during storage depends largely on the genotype. The results are in the agreement with the findings of Verma and Jha (1990) and Kumar et al. (1995). They observed that the extent of weight loss during storage was dependent on genotypes. Among seven commercial potato cultivars, viz. Kufri Ashoka, Kufri Jawahar, Kufri Badshah, Kufri Pukhraj, Kufri Chandramukhi, 85-P-718 and JW-96, packed in gunny bags and stored at ambient temperature $\left(29 \pm 6^{\circ}\right.$ C).The different behaviour of varieties with reference to physiological loss in weight might be due to genetic factors (Patel et al., 2006). The variety Kufri Pushkar showed the lowest physiological loss in weight as compared to other varieties. The maximum value for cumulative physiological loss in weight was observed in variety Kufri Bahar (12.07\%), followed by Kufri Pukhraj 
Table 1. Effect of varieties and tuber size on physiological loss in weight (\%) of potato during storage under ambient conditions.

\begin{tabular}{|c|c|c|c|c|c|c|c|c|c|c|}
\hline \multirow[t]{2}{*}{ Treatments } & & \multicolumn{9}{|c|}{ Storage period (days) } \\
\hline & & 10 & 20 & 30 & 40 & $\mathbf{5 0}$ & 60 & 70 & 80 & 90 \\
\hline \multirow{3}{*}{$\begin{array}{l}\text { Kufri } \\
\text { Badshah }\left(\mathrm{V}_{1}\right)\end{array}$} & $\mathrm{S}_{1}$ & 0.43 & 0.95 & 1.52 & 2.05 & 3.56 & 4.85 & 6.77 & 7.85 & 8.40 \\
\hline & $\mathrm{S}_{2}$ & 0.63 & 1.36 & 1.92 & 2.75 & 4.25 & 5.72 & 7.25 & 8.70 & 9.20 \\
\hline & $\mathrm{S}_{3}$ & 0.87 & 1.55 & 2.51 & 3.42 & 4.82 & 6.48 & 8.30 & 9.40 & 9.85 \\
\hline \multirow{2}{*}{ Mean $\mathrm{V}_{1}$} & & 0.64 & 1.28 & 1.98 & 2.74 & 4.21 & 5.68 & 7.35 & 8.65 & 9.15 \\
\hline & $\mathrm{S}_{1}$ & 0.71 & 1.74 & 2.26 & 3.45 & 5.35 & 7.50 & 9.00 & 10.62 & 11.35 \\
\hline \multirow{2}{*}{ Bahar $\left(V_{2}\right)$} & $\mathrm{S}_{2}$ & 0.95 & 1.85 & 2.65 & 3.75 & 5.75 & 7.80 & 9.52 & 11.43 & 12.00 \\
\hline & $\mathrm{S}_{3}$ & 1.20 & 2.20 & 3.10 & 4.15 & 6.25 & 8.20 & 10.15 & 12.40 & 12.85 \\
\hline \multicolumn{2}{|l|}{ Mean $V_{2}$} & 0.95 & 1.93 & 2.67 & 3.78 & 5.78 & 7.83 & 9.56 & 11.48 & 12.07 \\
\hline \multirow{3}{*}{$\begin{array}{l}\text { Kufri } \\
\text { Pukhraj }\left(V_{3}\right)\end{array}$} & $\mathrm{S}_{1}$ & 0.65 & 1.24 & 2.15 & 3.05 & 4.80 & 6.68 & 8.16 & 10.00 & 10.60 \\
\hline & $\mathrm{S}_{2}$ & 0.92 & 1.75 & 2.52 & 3.55 & 5.10 & 6.75 & 8.54 & 10.35 & 10.85 \\
\hline & $\mathrm{S}_{3}$ & 1.11 & 1.98 & 2.90 & 4.01 & 5.80 & 7.25 & 8.90 & 10.62 & 12.00 \\
\hline \multirow{2}{*}{ Mean $V_{3}$} & & 0.89 & 1.65 & 2.52 & 3.53 & 5.23 & 6.89 & 8.53 & 10.32 & 11.15 \\
\hline & $\mathrm{S}_{1}$ & 0.32 & 0.50 & 1.15 & 1.82 & 2.96 & 4.05 & 4.78 & 6.20 & 6.65 \\
\hline \multirow{2}{*}{$\begin{array}{l}\text { Kufri } \\
\text { Pushkar }\left(\mathrm{V}_{4}\right)\end{array}$} & $\mathrm{S}_{2}$ & 0.38 & 0.75 & 1.42 & 2.15 & 3.40 & 4.42 & 5.52 & 7.10 & 7.68 \\
\hline & $\mathrm{S}_{3}$ & 0.45 & 1.00 & 1.77 & 2.68 & 4.00 & 5.15 & 6.15 & 7.52 & 8.00 \\
\hline \multirow[t]{2}{*}{ Mean $V_{4}$} & & 0.38 & 0.75 & 1.44 & 2.21 & 3.45 & 4.54 & 5.48 & 6.94 & 7.44 \\
\hline & $S_{1}$ & 0.52 & 1.10 & 1.77 & 2.59 & 4.16 & 5.77 & 7.11 & 8.67 & 9.25 \\
\hline \multirow[t]{2}{*}{ Mean of Size } & $S_{2}$ & 0.72 & 1.42 & 2.12 & 3.05 & 4.62 & 6.17 & 7.70 & 9.40 & 9.93 \\
\hline & $S_{3}$ & 0.90 & 1.68 & 2.57 & 3.56 & 5.21 & 6.77 & 8.37 & 10.00 & 10.68 \\
\hline \multicolumn{11}{|c|}{ C.D. at $1 \%$ level of significance } \\
\hline \multicolumn{2}{|c|}{ Variety } & 0.05 & 0.10 & 0.17 & 0.10 & 0.18 & 0.12 & 0.21 & 0.26 & 0.20 \\
\hline \multicolumn{2}{|l|}{ Size } & 0.04 & 0.05 & 0.16 & 0.18 & 0.17 & 0.11 & 0.18 & 0.22 & 0.18 \\
\hline \multicolumn{2}{|l|}{ Variety x Size } & 0.17 & 0.11 & 0.14 & 0.18 & 0.16 & 0.21 & 0.40 & 0.45 & 0.35 \\
\hline
\end{tabular}

Values in parentheses are transformed values

Table 2. Effect of varieties and tuber size on decay loss during storage under ambient conditions.

\begin{tabular}{|c|c|c|c|c|c|}
\hline \multirow[t]{2}{*}{ Treatments } & & \multicolumn{2}{|c|}{ On number basis (\%) } & \multicolumn{2}{|c|}{ On weight basis (\%) } \\
\hline & & $\mathbf{8 0}$ & 90 & 80 & 90 \\
\hline \multirow{3}{*}{ Kufri Badshah $\left(\mathrm{V}_{1}\right)$} & $\overline{\mathrm{S}_{\mathrm{I}}}$ & $0.00(1.81)$ & 1.40 & $0.00(1.81)$ & 2.00 \\
\hline & $\mathrm{S}_{2}$ & $0.00(1.81)$ & 4.28 & $0.00(1.81)$ & 2.74 \\
\hline & $\mathrm{S}_{3}$ & $2.88(9.69)$ & 8.93 & $2.48(9.02)$ & 7.88 \\
\hline \multirow{2}{*}{ Mean $\mathrm{V}_{1}$} & & $0.96(4.44)$ & 4.87 & $0.82(4.21)$ & 4.21 \\
\hline & $\mathrm{S}_{1}$ & $0.00(1.81)$ & 1.95 & $0.00(1.81)$ & 2.38 \\
\hline \multirow{2}{*}{ Kufri Bahar $\left(\mathrm{V}_{2}\right)$} & $\mathrm{S}_{2}$ & $0.00(1.81)$ & 4.07 & $0.00(1.81)$ & 5.12 \\
\hline & $\mathrm{S}_{3}$ & $0.00(1.81)$ & 5.77 & $0.00(1.81)$ & 6.25 \\
\hline \multirow{2}{*}{ Mean $\mathrm{V}_{2}$} & & $0.00(1.81)$ & 3.93 & $0.00(1.81)$ & 4.58 \\
\hline & $\mathrm{S}_{1}$ & $0.00(1.81)$ & 1.61 & $0.00(1.81)$ & 3.22 \\
\hline \multirow{2}{*}{ Kufri Pukhraj $\left(\mathrm{V}_{3}\right)$} & $\mathrm{S}_{2}$ & $0.00(1.81)$ & 5.28 & $0.00(1.81)$ & 6.15 \\
\hline & $\mathrm{S}_{3}$ & $1.00(5.65)$ & 7.26 & $0.78(5.05)$ & 8.42 \\
\hline \multirow[t]{2}{*}{ Mean $V_{3}$} & & $0.33(3.09)$ & 4.72 & $0.26(2.89)$ & 5.93 \\
\hline & $\mathrm{S}_{1}$ & $0.00(1.81)$ & 2.96 & $0.00(1.81)$ & 3.65 \\
\hline \multirow[t]{2}{*}{ Kufri Pushkar $\left(\mathrm{V}_{4}\right)$} & $\mathrm{S}_{2}$ & $3.55(10.85)$ & 8.75 & $3.25(10.11)$ & 10.08 \\
\hline & $\mathrm{S}_{3}$ & $4.88(12.75)$ & 11.53 & $4.60(11.74)$ & 12.44 \\
\hline \multirow[t]{2}{*}{ Mean $\mathrm{V}_{4}$} & & $2.81(8.47)$ & 7.75 & $2.62(7.89)$ & 8.72 \\
\hline & $S_{1}$ & $0.00(1.81)$ & 1.98 & $0.00(1.81)$ & 2.81 \\
\hline \multirow[t]{2}{*}{ Mean of Size } & $S_{2}$ & $0.89(4.07)$ & 5.96 & $0.81(3.88)$ & 6.02 \\
\hline & $S_{3}$ & $1.94(7.48)$ & 8.37 & $1.97(6.91)$ & 8.75 \\
\hline \multicolumn{6}{|c|}{ C.D. at $1 \%$ level of significance } \\
\hline \multicolumn{2}{|c|}{ Variety } & 0.57 & 0.69 & 0.36 & 0.77 \\
\hline \multicolumn{2}{|l|}{ Size } & 0.55 & 0.60 & 0.31 & 0.66 \\
\hline \multicolumn{2}{|l|}{ Variety x Size } & 0.99 & 1.20 & 0.62 & 1.33 \\
\hline
\end{tabular}

Values in parentheses are transformed values

$(11.15 \%)$ and the minimum in Kufri Badshah (9.15\%) followed by Kufri Pushkar (7.44\%) at the end of experiment as shown in Table 1. The size of potato tubers had significant variation in physiological loss in weight. The small sized tubers can be stored longer as compared to large and medium sized tubers. Among the tuber sizes, small sized tubers showed the minimum cumulative physiological loss in weight $(8.67 \%)$ in comparison to medium $(9.40 \%)$ and large sized tubers $(10.00 \%)$ on 90 th day of storage under ambient conditions (Table 1). An increase in physiological loss in weight was noticed in tubers of all the varieties with increasing storage period, which was obviously due to loss of moisture from the tubers through transpiration and utilization of reserved 
Table 3. Effect of varieties and tuber size on sprouting loss (\%) on weight basis of potato during storage under ambient conditions.

\begin{tabular}{|c|c|c|c|c|c|}
\hline \multirow[t]{2}{*}{ Treatments } & & \multicolumn{4}{|c|}{ Storage period (days) } \\
\hline & & 60 & 70 & 80 & 90 \\
\hline \multirow{3}{*}{ Kufri Badshah $\left(\mathrm{V}_{1}\right)$} & Small $\left(\mathrm{S}_{1}\right)$ & $20.1(26.80)$ & $32.0(36.25)$ & $40.7(39.62)$ & $44.2(42.09)$ \\
\hline & Medium $\left(S_{2}\right)$ & $30.0(33.20)$ & $42.0(40.38)$ & $50.0(45.73)$ & $57.4(49.25)$ \\
\hline & Large $\left(\mathrm{S}_{3}\right)$ & $39.0(39.10)$ & $58.9(48.43)$ & $65.0(54.01)$ & $71.7(57.84)$ \\
\hline \multirow[t]{2}{*}{ Mean $\mathrm{V}_{1}$} & & $29.7(30.02)$ & $44.3(41.69)$ & $51.9(46.45)$ & $57.8(49.73)$ \\
\hline & Small $\left(\mathrm{S}_{1}\right)$ & $55.3(48.37)$ & $75.0(61.19)$ & $100.0(89.39)$ & $100.0(89.39)$ \\
\hline \multirow{2}{*}{ Kufri Bahar $\quad\left(V_{2}\right)$} & Medium $\left(S_{2}\right)$ & $67.1(55.42)$ & $78.4(63.61)$ & $100.0(89.39)$ & $100.0(89.39)$ \\
\hline & Large $\left(\mathrm{S}_{3}\right)$ & $87.7(70.23)$ & $100.0(89.39)$ & $100.0(89.39)$ & $100.0(89.39)$ \\
\hline \multirow{2}{*}{ Mean $\mathrm{V}_{2}$} & & $70.0(58.01)$ & $84.5(71.40)$ & $100.0(89.39)$ & $100.0(89.39)$ \\
\hline & Small $\left(\mathrm{S}_{1}\right)$ & $47.3(44.21)$ & $62.0(50.40)$ & $69.0(54.99)$ & $76.0(59.65)$ \\
\hline \multirow{2}{*}{ Kufri Pukhraj $\left(V_{3}\right)$} & $\operatorname{Medium}\left(\mathrm{S}_{2}\right)$ & $60.0(49.52)$ & $68.0(54.50)$ & $76.0(59.87)$ & $80.6(63.81)$ \\
\hline & Large $\left(\mathrm{S}_{3}\right)$ & $67.6(56.02)$ & $77.0(60.11)$ & $82.0(65.12)$ & $88.6(70.22)$ \\
\hline \multirow[t]{2}{*}{ Mean $\mathrm{V}_{3}$} & & $58.3(49.92)$ & $69.0(55.00)$ & $75.7(59.99)$ & $81.7(64.56)$ \\
\hline & Small $\left(\mathrm{S}_{1}\right)$ & $8.0(15.54)$ & $12.6(20.75)$ & $20.3(26.76)$ & $25.3(30.18)$ \\
\hline \multirow[t]{2}{*}{ Kufri Pushkar $\left(V_{4}\right)$} & Medium $\left(\mathrm{S}_{2}\right)$ & $21.0(26.24)$ & $31.5(34.89)$ & $44.0(41.88)$ & $52.3(46.30)$ \\
\hline & Large $\left(\mathrm{S}_{3}\right)$ & $38.5(37.27)$ & $43.0(42.34)$ & $56.5(48.72)$ & $65.0(53.71)$ \\
\hline \multirow[t]{2}{*}{ Mean $\mathrm{V}_{4}$} & & $22.5(26.35)$ & $29.0(32.66)$ & $40.3(39.12)$ & $47.5(43.40)$ \\
\hline & $\operatorname{Small}\left(S_{l}\right)$ & $43.5(33.73)$ & $45.4(42.15)$ & $57.5(59.22)$ & $61.4(55.33)$ \\
\hline \multirow[t]{2}{*}{ Mean of Size } & Medium $\left(S_{2}\right)$ & $59.4(41.09)$ & $55.0(48.34)$ & $67.5(54.75)$ & $72.6(62.19)$ \\
\hline & Large $\left(S_{3}\right)$ & $77.6(50.65)$ & $69.7(60.10)$ & $75.9(64.31)$ & $81.3(67.79)$ \\
\hline \multicolumn{6}{|c|}{ C.D. at $1 \%$ level of significance } \\
\hline \multicolumn{2}{|c|}{ Variety } & 0.75 & 1.17 & 0.78 & 0.75 \\
\hline \multicolumn{2}{|l|}{ Size } & 0.65 & 1.01 & 0.67 & 0.64 \\
\hline \multicolumn{2}{|l|}{ Variety x Size } & 1.30 & 2.03 & 1.35 & 1.29 \\
\hline
\end{tabular}

Values in parentheses are transformed values

food material in respiration process. These results confirm the findings of Mehta and Singh (2002). Mehta and Singh (2002) recorded that the mean physiological loss in weight increased from 7.5 to $13.7 \%$ between 90 and 120 days of storage of potato tubers, when tubers of four potato varieties were stored for 180 days during 2003 and 2004 storage seasons.

2. Decay loss (\%): The loss due to decaying of potato tubers on both number and weight basis was recorded at an interval of 10 days during storage and expressed in cumulative percentage as shown in Table 2. Microbial spoilage together with water loss and biochemical changes is responsible for the deterioration of freshly harvested produce during storage. The decay loss might be due to vulnerable nature of potato tubers to different disease causing organisms and the attack of pests during storage or carried over from the field, which got sufficient time to multiply and grew with increasing storage period.

i) On weight basis (\%): The decay loss on weight basis differed significantly with the varieties. The maximum decay loss was observed in variety Kufri Pushkar (7.89 and $8.72 \%$ ) and minimum in Kufri Bahar (0.00 and $4.58 \%$ ) on 80 th and 90th day of storage period, respectively (Table 2). Large sized potato tubers showed the maximum decay loss (6.91 and 8.75\%) and small sized tubers showed the minimum decay loss $(0.00$ and $2.81 \%$ ) on 80 th day and at the end of storage the period, respectively. In a post-harvest study, Mangal et al. (1999) recorded decay loss from 1.9 to $5.7 \%$ when two kilograms of uniform-sized tubers of seven commercial potato cultivars, viz. Kufri Ashoka, Kufri Jawahar, Kufri Badshah, Kufri Pukhraj, Kufri Chandramukhi, 85-P-718 and JW-96, were packed in gunny bags and stored under ambient room temperature $\left(29 \pm 6^{\circ} \mathrm{C}\right)$ conditions. Ezekiel et al. (2002) observed that on farm storage, methods are economical and practical but they are not efficient because of higher losses due to increased rotting (10-40\%).

ii) On number basis (\%): The maximum cumulative decay loss on number basis was observed in variety Kufri Pushkar (4.88 and $11.53 \%$ ), while it was minimum in Kufri Bahar (0.00 and 3.93\%) on 80th and 90th day of storage, respectively. The decay loss on number basis due to size of the tubers differed significantly. The maximum cumulative decay loss was recorded with large sized potato tubers (2.19 and $8.37 \%$ ), whereas, it was minimum with small sized tubers $(0.00$ and $1.98 \%)$ on 80 th and 90th of storage, respectively as shown in Table 2 . This might be due to the reason that smaller tubers were immature than medium and larger ones since the smaller tubers formed bit later than medium and larger tubers, and small sized tubers also showed better storage life than larger tubers due to the presence of small amount of moisture. The maximum number of rotten tuber was found from large sized tubers and minimum from small sized tubers, whereas, medium sized tubers produced the average results on rotting at 60,90 and 120 DAS, respectively. The storage of potato zero days after haulm killing showed the maximum number of rotten tubers due to its immaturity and small tubers showed better results than the larger tubers due to the presence of small amount of moisture compared to larger tubers (Nipa et al., 2013; Small and Pahl, 2012).

Sprouting loss (\%): Sprouting of tubers during storage is detrimental to their nutritive value and marketability. Some of the undesirable changes that occur during sprouting are weight loss, shrinkage and 
Table 4. Effect of varieties and tuber size on sprouting (\%) on number basis and sprout weight at $90^{\text {th }}$ day of potato tubers during storage under ambient conditions.

\begin{tabular}{|c|c|c|c|c|c|}
\hline \multirow[t]{2}{*}{ Treatments } & \multicolumn{5}{|c|}{ Storage period (days) } \\
\hline & 60 & 70 & 80 & 90 & At 90 ${ }^{\text {th }}$ day \\
\hline \multicolumn{6}{|l|}{ Kufri Badshah $\left(\mathrm{V}_{1}\right)$} \\
\hline Small $\left(\mathrm{S}_{1}\right)$ & $6.9(14.90)$ & $12.2(20.46)$ & $19.3(26.04)$ & $40.5(40.37)$ & 2.15 \\
\hline $\operatorname{Medium}\left(\mathrm{S}_{2}\right)$ & $21.2(27.40)$ & $32.3(34.60)$ & $48.7(44.21)$ & $55.7(48.23)$ & 5.38 \\
\hline Large $\left(\mathrm{S}_{3}\right)$ & $56.6(48.04)$ & $77.9(62.20)$ & $97.2(80.34)$ & $100.0(89.40)$ & 9.32 \\
\hline Mean & $28.2(30.11)$ & $40.8(39.08)$ & $55.1(50.20)$ & $65.3(59.33)$ & 5.62 \\
\hline \multicolumn{6}{|l|}{ Kufri Bahar $\left(\mathrm{V}_{2}\right)$} \\
\hline Small $\left(\mathrm{S}_{1}\right)$ & $65.5(53.99)$ & $83.9(66.32)$ & $100.0(89.39)$ & $100.0(89.39)$ & 13.60 \\
\hline $\operatorname{Medium}\left(\mathrm{S}_{2}\right)$ & $74.1(59.41)$ & $86.3(68.25)$ & $100.0(89.39)$ & $100.0(89.39)$ & 17.55 \\
\hline Large $\left(\mathrm{S}_{3}\right)$ & $90.0(71.59)$ & $100.0(89.40)$ & $100.0(89.39)$ & $100.0(89.39)$ & 20.00 \\
\hline Mean & $76.7(61.67)$ & $90.1(74.65)$ & $100.0(89.39)$ & $100.0(89.39)$ & 17.05 \\
\hline \multicolumn{6}{|l|}{ Kufri Pukhraj $\left(\mathrm{V}_{3}\right)$} \\
\hline Small $\left(\mathrm{S}_{1}\right)$ & $48.3(44.01)$ & $61.8(51.80)$ & $67.8(55.15)$ & $85.5(67.60)$ & 10.67 \\
\hline $\operatorname{Medium}\left(\mathrm{S}_{2}\right)$ & $57.3(49.17)$ & $70.4(57.04)$ & $81.5(64.50)$ & $90.9(72.37)$ & 12.00 \\
\hline Large $\left(\mathrm{S}_{3}\right)$ & $73.5(59.90)$ & $84.9(66.76)$ & $90.6(72.08)$ & $94.7(77.84)$ & 14.65 \\
\hline Mean & $59.7(51.02)$ & $72.4(58.53)$ & $80.0(63.91)$ & $90.4(72.60)$ & 12.44 \\
\hline \multicolumn{6}{|l|}{ Kufri Pushkar $\left(V_{4}\right)$} \\
\hline Small $\left(\mathrm{S}_{1}\right)$ & $19.3(26.05)$ & $31.9(34.62)$ & $40.3(39.35)$ & $44.8(42.24)$ & 1.26 \\
\hline Medium $\left(S_{2}\right)$ & $24.0(29.31)$ & $39.0(38.64)$ & $53.4(46.93)$ & $58.4(49.81)$ & 4.32 \\
\hline Large $\left(\mathrm{S}_{3}\right)$ & $37.4(37.70)$ & $55.1(47.91)$ & $74.7(59.76)$ & $79.9(62.48)$ & 7.55 \\
\hline Mean & $26.9(31.02)$ & $42.0(40.40)$ & $56.1(48.68)$ & $61.0(51.51)$ & 4.38 \\
\hline \multicolumn{6}{|l|}{ Mean of Size } \\
\hline Small $\left(\mathrm{S}_{1}\right)$ & $35.0(34.74)$ & $47.4(43.30)$ & $56.8(52.48)$ & $67.7(59.90)$ & 6.92 \\
\hline $\operatorname{Medium}\left(\mathrm{S}_{2}\right)$ & $44.2(41.32)$ & $57.0(49.63)$ & $70.9(61.26)$ & $76.2(64.95)$ & 9.81 \\
\hline Large $\left(\mathrm{S}_{3}\right)$ & $64.4(54.30)$ & $79.5(66.53)$ & $90.6(75.39)$ & $93.7(79.78)$ & 12.88 \\
\hline \multicolumn{6}{|c|}{ C.D. at $1 \%$ level of significance } \\
\hline Variety & 0.83 & 0.34 & 0.36 & 0.63 & 0.11 \\
\hline Size & 0.72 & 0.29 & 0.31 & 0.55 & 0.09 \\
\hline Variety x Size & 1.44 & 0.58 & 0.62 & 1.09 & 0.19 \\
\hline
\end{tabular}

Values in parentheses are angular transformed values

loss of nutritive value. Under ordinary room temperature conditions, sprouting is a very serious problem in potato tubers. The potato tubers immediately after harvesting do not sprout since they remain in a dormant state. Sprouting intensity depends on time when the natural dormancy period is fulfilled and on temperature, humidity and atmospheric composition in the storage. The sprouting loss was significantly influenced due to the effect of variety, size and their combination on 90th day of storage. Sprouting started on $60^{\text {th }}$ day of storage in all the treatment combinations.

i) On weight basis: All the varieties with respect to sprouting loss differed significantly from each other. Kufri Bahar showed the significantly maximum cumulative sprouting loss (70.0, 84.5, 100.0 and $100.0 \%$ ), while Kufri Pushkar showed the minimum cumulative sprouting loss $(22.5,29.0,40.3$ and $47.5 \%)$ on $60^{\text {th }}, 70^{\text {th }}, 80^{\text {th }}$ and $90^{\text {th }}$ day of storage, respectively (Table 3). Kufri Bahar had a shortest dormancy period than the other three varieties, thus, the percent sprouting loss was highest in Kufri Bahar under ambient conditions. Similar results were reported by Sukumaran and Verma (1993). The size of potato tubers differed significantly with respect to sprouting loss on weight basis. The small sized tubers had the significantly lowest sprouting loss $(32.7,45.4,57.5$ and $61.37 \%)$, and large sized tubers the highest sprouting loss $(58.2,69.7,75.8$ and $81.3 \%$ ) on 60 th, 70th, 80th and 90th day of experiment, respectively. The length of dormancy decreases with the increase in tuber size. The long dormancy and reduced sprout growth might be the reasons for lower physiological loss in variety Kufri Pushkar during storage. Sprout weight is known to be positively associated with physiological loss in weight (Mehta and Kaul, 1997) since the epidermis of sprouts is about 100 times more permeable to water as compared to the tuber skin (Burton et al., 1992).

ii) On number basis: The data pertaining to sprouting loss $(\%)$ on number basis have been presented in Table 4. The percent sprouting loss on number basis differed significantly with variety, size and their interaction. The extent of cumulative percent loss due to sprouting increased up to the end of storage, however, the extent of sprouting loss was more from 60 to 70 and 80 to 90 days of storage period.

The data pertaining to sprouting loss on number basis differed significantly with the variety. The percent cumulative sprout loss on number basis was noted significantly highest in Kufri Bahar (76.7, 90.1, 100.0 and $100.0 \%$ ) significantly minimum in Kufri Pushkar (26.9, $42.0,56.1$ and $61.0 \%$ ) on first, second, third and fourth observation taken on 60th, 70th, 80th and 90th day of storage, respectively (Table 4). The sprouting loss on number basis among the tuber sizes differed significantly, 
Table 5. Effect of varieties and tuber size on total loss (\%) of potato during storage under ambient conditions.

\begin{tabular}{|c|c|c|c|c|c|c|c|c|c|c|}
\hline \multirow[t]{2}{*}{ Treatments } & & \multicolumn{9}{|c|}{ Storage period (days) } \\
\hline & & 10 & 20 & 30 & 40 & $\mathbf{5 0}$ & 60 & 70 & 80 & 90 \\
\hline \multirow{3}{*}{$\begin{array}{l}\text { Kufri Badshah } \\
\left(\mathrm{V}_{1}\right)\end{array}$} & $\mathrm{S}_{\mathrm{I}}$ & 0.43 & 0.95 & 1.52 & 2.05 & 3.56 & 4.85 & 6.77 & 7.85 & 10.40 \\
\hline & $\mathrm{S}_{2}$ & 0.63 & 1.36 & 1.92 & 2.75 & 4.25 & 5.72 & 7.25 & 11.18 & 11.94 \\
\hline & $\mathrm{S}_{3}$ & 0.87 & 1.55 & 2.51 & 3.42 & 4.82 & 6.48 & 8.30 & 11.88 & 17.73 \\
\hline \multirow[t]{2}{*}{ Mean $\mathrm{V}_{1}$} & & 0.64 & 1.28 & 1.98 & 2.74 & 4.21 & 5.68 & 7.35 & 10.30 & 13.35 \\
\hline & $\mathrm{S}_{1}$ & 0.71 & 1.74 & 2.26 & 3.45 & 5.35 & 7.50 & 9.00 & 10.60 & 13.68 \\
\hline \multirow[t]{2}{*}{ Kufri Bahar $\left(V_{2}\right)$} & $\mathrm{S}_{2}$ & 0.95 & 1.85 & 2.65 & 3.75 & 5.75 & 7.80 & 9.52 & 11.40 & 17.12 \\
\hline & $\mathrm{S}_{3}$ & 1.20 & 2.20 & 3.10 & 4.15 & 6.25 & 8.20 & 10.1 & 12.40 & 19.05 \\
\hline \multirow[t]{2}{*}{ Mean $V_{2}$} & & 0.95 & 1.93 & 2.67 & 3.78 & 5.78 & 7.83 & 9.56 & 11.40 & 16.62 \\
\hline & $\mathrm{S}_{1}$ & 0.65 & 1.24 & 2.15 & 3.05 & 4.80 & 6.68 & 8.16 & 10.00 & 13.82 \\
\hline \multirow{2}{*}{ Kufri Pukhraj $\left(V_{3}\right)$} & $\mathrm{S}_{2}$ & 0.92 & 1.75 & 2.52 & 3.55 & 5.10 & 6.75 & 8.54 & 10.30 & 16.95 \\
\hline & $\mathrm{S}_{3}$ & 1.11 & 1.98 & 2.90 & 4.01 & 5.80 & 7.25 & 8.90 & 11.38 & 20.42 \\
\hline \multirow[t]{2}{*}{ Mean $V_{3}$} & & 0.89 & 1.65 & 2.52 & 3.53 & 5.23 & 6.89 & 8.53 & 10.56 & 17.06 \\
\hline & $\mathrm{S}_{1}$ & 0.32 & 0.50 & 1.15 & 1.82 & 2.96 & 4.05 & 4.78 & 6.20 & 10.30 \\
\hline \multirow[t]{2}{*}{ Kufri Pushkar $\left(\mathrm{V}_{4}\right)$} & $\mathrm{S}_{2}$ & 0.38 & 0.75 & 1.42 & 2.15 & 3.40 & 4.42 & 5.52 & 10.35 & 17.76 \\
\hline & $\mathrm{S}_{3}$ & 0.45 & 1.00 & 1.77 & 2.68 & 4.00 & 5.15 & 6.15 & 12.12 & 20.44 \\
\hline \multirow[t]{2}{*}{ Mean $\mathrm{V}_{4}$} & & 0.38 & 0.75 & 1.44 & 2.21 & 3.45 & 4.54 & 5.48 & 9.57 & 16.16 \\
\hline & $\mathrm{S}_{1}$ & 0.52 & 1.10 & 1.77 & 2.59 & 4.16 & 5.77 & 7.11 & 8.66 & 12.05 \\
\hline \multirow[t]{2}{*}{ Mean of Size } & $\mathrm{S}_{2}$ & 0.72 & 1.42 & 2.12 & 3.05 & 4.62 & 6.17 & 7.70 & 10.80 & 19.41 \\
\hline & $\mathrm{S}_{3}$ & 0.90 & 1.68 & 2.57 & 3.56 & 5.21 & 6.77 & 8.37 & 11.95 & 8.75 \\
\hline \multicolumn{11}{|c|}{ C.D. at $1 \%$ level of significance } \\
\hline Variety & & 0.05 & 0.10 & 0.17 & 0.10 & 0.18 & 0.12 & 0.21 & 1.01 & 1.39 \\
\hline Size & & 0.04 & 0.05 & 0.16 & 0.18 & 0.17 & 0.11 & 0.18 & 0.88 & 1.20 \\
\hline Variety x Size & & 0.17 & 0.11 & 0.14 & 0.18 & 0.16 & 0.21 & 0.40 & 1.75 & 2.40 \\
\hline
\end{tabular}

which was significantly lower in smaller tubers than medium and larger tubers. The minimum cumulative sprouting loss was observed in small sized tubers (35.0, 47.4, 56.8 , and $67.7 \%$ ) and the highest cumulative percent sprouting loss was noticed in large sized tubers (64.4, $79.5,90.6$ and $93.7 \%$ ) on 60th, 70th, 80th and 90th day of storage, respectively. Higher rate of sprouting in largesized tubers might be attributed to decreased duration of dormancy due to their greater age as they formed earlier than the small sized tubers and smaller tubers were formed later than the larger tubers and therefore had longer dormancy period. The increasing number of sprouts with increasing size of potato tubers could be attributed to more number of eyes on larger tubers with large surface area.

Sprout weight (g): The perusal of data pertaining to sprout weight $(\mathrm{g})$ of tubers (Table 4) estimated at end of the experiment by removal of sprouts from the potato tubers during storage. The data pertaining to sprout weight differed significantly with the variety. The sprout weight was noted significantly highest in Kufri Bahar (17.05g) significantly minimum in Kufri Pushkar (4.38g) at the end of storage. The sprout weight differed significantly, which was significantly lower in smaller tubers than medium and larger tubers. The minimum sprout weight was observed in small sized tubers $(6.92 \mathrm{~g})$ and the highest sprout weight was noticed in large sized tubers $(12.88 \mathrm{~g})$ on 90 th day of storage. The interaction between variety and size was statistically significant for sprout weight at the end of storage. The large sized tubers of Kufri Bahar $(20.00 \mathrm{~g})$ contributed the significantly maximum sprout weight, whereas, small sized tubers of Kufri Pushkar (1.26g) contributed the significantly minimum sprout weight at the end of the storage (Table 4).
Total loss (\%): The extent of total loss in weight caused by physiological loss in weight and decay loss during storage is presented in Table 5. The data indicate that the percent total loss increased significantly with increasing storage length, which might be due to continuous loss of water through transpiration, respiration, sprouting and decaying of tubers, particularly under ambient temperature conditions, and this increase was higher towards later stages as compared to earlier stage of storage period which was obviously due to the incidence of decaying.

The varieties had a significant effect on percent total loss in weight during entire storage. Among the varieties, Kufri Badshah was found the best with minimum cumulative total loss $(13.35 \%)$. This minimum total loss could possibly be due to lowering of decay loss in Kufri Badshah, whereas, Kufri Pukhraj was noticed the poorest one with maximum cumulative total loss (17.06\%) closely followed by Kufri Bahar and Kufri Pushkar during entire study of storage as shown in Table 5. The variety Kufri Bahar was at par with Kufri Pushkar with respect to cumulative total weight loss, as they had no significant difference in their cumulative total loss.

The perusal of data reveals that potato tuber size also had significant effect on total loss at all the observations taken during entire course of storage study. Among the sizes of tubers for storage, the small sized tubers proved significantly better over rest of the tuber sizes. The minimum cumulative total loss $(12.05 \%)$ was recorded with small sized tubers, whereas, the maximum cumulative total loss $(19.41 \%)$ was recorded with large sized tubers at the end of experimentation. The sudden increase in total loss at later part of storage period was obviously due to the incidence of decaying. Among the sizes, small sized tubers 
showed less total loss, which was due to lowering of physiological loss in weight and decaying of tubers as compared to medium and large sized tubers.

Black or hollow heart: In present study, black or hollow heart was completely absent in all the possible treatment combinations, which might be attributed to bit lower temperature $\left(<38^{\circ} \mathrm{C}\right)$ due to proper cross ventilation in the room where the potatoes were stored. Although this phenomenon is a major characteristic of the varieties producing large size tubers but black or hollow heart develops when the potato tubers are harvested on hotter days and stored at a temperature more than $40^{\circ} \mathrm{C}$, which was not observed in the storehouse during experimentation.

General appearance: The minimum shrinkage was noticed in Kufri Pushkar and maximum in Kufri Bahar. Visible rating of firmness showed shriveled condition of heaped potatoes after 90 days of storage. Tuber weight loss more than $10 \%$ reduces the marketability of potatoes because of their shriveled appearance. Visual rating for appearance showed that the tubers of potato cultivars remained firm up to 105 days even at room temperature (Mehta, 2006). The size of potato tuber significantly influenced the days to start shriveling as the large sized tubers shriveled earlier than the small sized tubers (Nipa et al., 2013). Weight loss up to $10 \%$ was considered acceptable because of no visible shriveling of tubers, but at higher weight loss, shriveling took place, which reduced the market value of table potatoes (Mehta and Ezekiel, 2010).

\section{Conclusion}

The physiological loss in weight increased with the increase in storage period. The larger tubers lost more weight than the medium and smaller. The decay loss also increased with the increase in storage period and was observed minimum in Kufri Badshah and maximum in Kufri Pushkar. The decay was more in larger tubers than smaller tubers. The sprouting increased with the progress in storage period and was completely $100 \%$ in Kufri Bahar. Minimum sprouting was observed in Kufri Pushkar. The percent sprouting was more in larger tubers than medium or smaller tubers. Based on the results, it can be concluded that potato tubers with the small size could be stored longer than the large and medium sized tubers with minimum post-harvest quality loss.

\section{REFERENCES}

Burton, W.G., Van Es, A. and Hartmans, K.J. (1992). The Physics and Physiology of storage. In: The potato Crop: The Scientific Bases for Improvement (Ed. Harris, P.M). Chapman \& Hall, London, UK, pp. 608-727.

Ezekiel, R., Dahiya, P.S. and Shekhawat, G.S. (2002). Traditional Methods of Potato Storage in the Malwa Region of Madhya Pradesh, Technical Bulletin, No. 57, Central Potato Research Institute, Shimla, India, p. 39.
Gautam, I.P., Khatri, B.B., Sharma, M.D., Thapa, R.B., Shreshtha, K. and Chaudhary, D. (2012). Evaluation of potato genotypes for keeping quality under ambient conditions in Nepal. Potato Journal, 39(2): 128-132.

Kumar, D., Kaul, H.N. and Singh, S.V. (1995). Keeping quality in advanced potato selections during non-refrigerated storage. Journal of the Indian Potato Association, 22: 105-108.

Kumar, R., Pandey, S.K. and Khurana, S.M.P. (2005). Keeping quality of potato processing cultivars during room temperature storage. Potato Journal, 32(1-2): 55-59.

Kang, G.S., Kumar, R.S., Pandey, K. and Khurana, S.M. P. (2001). Keeping quality of some advanced potato hybrids at room temperature storage. Journal of Indian Potato Association. 28: 137-38.

Mehta, A. and Kaul, H.N. (1997). Physiological weight loss in potatoes under non-refrigerated storage: contribution of respiration and transpiration. Journal of the Indian Potato Association, 24: 106-113.

Mehta, A. and Ezekiel, R. (2010). Non-refrigerated storage of potatoes. Potato Journal, 37(3-4): 87-99.

Mehta, A. and Singh, S.P. (2002). Physiological losses in potatoes under non-refrigerated storage: effect of N, P and K fertilizers. Journal of the Indian Potato Association, 29(34): $129-134$.

Mehta, A., Singh, S.V., Pandey, S.K. and Ezekiel, R. (2006). Storage behaviour of newly released potato cultivars under non-refrigerated storage. Potato Journal, 33(3-4): 158-161.

Nipa, J.S., Roy, T.S., Amin, A.K.M.R. and Hasanuzzaman, M. (2013). Effect of lifting time and tuber size on ambient storage performance of potato derived from true potato seed. International Journal of Sustainable Agriculture, 5 (1): $1-9$.

Mangal, J.L., Kumar J., Bhutani, R.D. and Khurana, S.C. (1999). Comparative shelf life of seven potato cultivars in evaporative cool chambers and ambient conditions. In: Proceedings of the Global Conference on Potato Research and Development, 6-11 December 1999, New Delhi, India, vol. 2 2002, pp. 1108-1110.

Patel, R.N., Kanbi, V.H., Patel, C.K., Patel, N.H. and Chaudhari, S.M. (2002). Room temperature storage of some advanced potato hybrids and varieties in the plains of $\mathrm{Gu}-$ jarat. Journal of Indian Potato Association 29: 159-61.

Patel, R.N., Patel, N.H., Pandey, S.K., Kanbi, V.H. and Patel, C.K. (2006). Yield performance and shelf life of some advanced potato hybrids in Gujarat. Potato Journal, 33(34): $149-150$.

Ranganna, S. (1977). Analysis of Fruits and Vegetable Products. Tata McGrew Hill Publication Co., New Delhi, India, pp. 29-31.

Small, D. and Pahl, K. (2012). Storage structures and ventilation. Adapted from Guide to Commercial Potato Production on the Canadian Prairies, Published by Western Potato Council, pp. 1-107.

Srivastava, M.P. and Tandon, R.N. (1968). Influence of temperature in Botrydiplodia rots of citrus and sapodilla. Indian Phytopathology, 21: 195-197.

Sukumaran, N.P. and Verma, S.C. (1993). Storage and processing of Potato. Advances in Horticulture, 7: 701-732.

Verma, V.S. and Jha, V.B. (1990). Evaluation of potato geno- 